\title{
What is Right and What is Wrong in the Darwinian Approach to the Study of Religion
}

\author{
Konrad Szocik \\ University of Information Technology and Management, \\ Rzeszow
}

\begin{abstract}
One of the greatest challenges for the study of cultural evolution is an explanation of processes and mechanisms of transmission of cultural traits. Darwinian approach is a promising and useful research program. However, it is worth to ask in what extent Darwinian account can provide appropriate and reliable explanation for origin and transmission of religious components. We can look for biological benefits provided by religious affiliation when we try to explain it in terms of survival and reproduction. However, biological evolutionary explanation cannot explain ultimately some unique human traits like religiosity. The focal point is if this approach can provide reliable explanation for specifically human cultural phenomena that only analogically can be found among some social animals. The key idea of this paper is that Darwinian approach to religion might explain only small part of human religiosity, and reliable explanation should combine Darwinian and cultural evolution, and cognitive account.
\end{abstract}

\section{INTRODUCTION}

Religion, religiosity, and religious components are still widely discussed topics. One view of religion is that it can be explained as a by-product of other adaptations and as an adaptation or something that possesses adaptedness. This topic refers to a more basic and fundamental question: is the Darwinian account an appropriate explanatory framework to explain religion? In this paper I am going to discuss some topics in the field of evolutionary study of religion but I go beyond the mentioned byproduct/adaptation distinction. My aim is to consider again the Darwinian account to the study of religion and to find some benefits and disadvantages that are a domain of this approach. I will focus mainly on the set

Social Evolution \& History, Vol. 18 No. 2, September 2019 210-228

(C) 2019 'Uchitel' Publishing House

DOI: $10.30884 / \mathrm{seh} / 2019.02 .11$ 
of problems that are a domain of cultural evolution. ${ }^{1}$ For this reason, I am going to discuss some conceptual challenges, advantages, and possible limitations that are associated with evolutionary explanations of culture including religion. My key idea is that the application of Darwinian account to the study of culture including religion requires too many exemptions, special interpretations, and extra explanations that drastically limits its applicability and effectiveness. After a brief inquiry I state that the Darwinian account may be applied only in some rare cases that makes this approach not very useful for the study of culture. My skepticism does not have metaphysical and ethical nature (I mean the critique of Darwinism based on naturalization and reduction of humans to animals) but purely definitional, conceptual, and in some sense, epistemological. I argue that there are too many differences between genetic and cultural changes to enable the simple transmission of Darwinian conceptual framework to the study of totally different cultural phenomena.

\section{CAUSAL AGENTS OF CULTURAL CHANGE. HIGH COMPLEXITY AND DIVERSITY OF CULTURAL TRAITS}

Cultural phenomena are so important and common in human species that talking about 'the extension of biology through culture' is obvious and accepted. I mean that culture may and should be explained by biology. Andrew Whiten et al. enumerate three general conceptual frameworks at the intersection of cultural and biological evolution. Cultural evolution works as a second and parallel system of inheritance. Cultural changes include not only vertical transmission like genetic changes but also horizontal and oblique ones. Both kinds of changes may interact in ways described by gene-culture co-evolutionary approach (Whiten et al. 2017: 7778). Culture is a function and/or ability that is possessed by humans and some non-human animal species. For this reason, this ability as a general and formal function may be considered in terms of Darwinian selection as a feature that has evolved for fitness maximization. The problem appears when scholars are going to study particular cultural phenomena and products of this general ability. One should mention here the distinction between capacity for culture and particular cultural contents. Capacity for culture is biological adaptation but some learning strategies may cause maladaptive cultural contents (Richerson and Boyd 2005: 373). Darwinian theory describes the concept of evolution by natural selection. This theory was primarily developed on the basis of observation of human artificial selection on some animal species, and as a theory that has described differences in shapes of beaks of finches at the Galapagos Islands. The starting point for this approach is thus a question about the causal agents of natural selection. Who or what is the causal factor of natural 
selection that acts on cultural traits including religious ones? In the case of building canoe, we may assume that the causal factor is the sea and the marine environmental conditions that require careful building and faithful copying of boats. In the case of Darwinian finches, the causal agent is a pool of available seeds affected by weather conditions. Natural random variation of various finches or any other birds is then limited, and only some kinds of beaks are preferred for survival dependent on available resources. Definitely, this theory is easy, convincing, and by that elegant but more with regard to 'simple' physical traits like speed, power, or agility. Psychological variants are much more difficult to explain. One of still debated and rather unresolved topics is the evolution of cooperation including altruism. The same we may say about cultural traits including religious ones. What is the causal agent of natural selection in regard to religious components? Natural selection may be defined as 'any interaction, major or minor, between the environment and an organism that is potentially harmful or damaging to it in the face of which some creatures fare better than others' (Rothman 2015: 16). Possessing faith in God is not the same like possessing good clothes that protect against cold, or good tools to achieve food or defend against predators. It is obvious that possible adaptive impact of religious components - if any - must be more indirect and more subtle. The puzzling question is if it could be really possible that natural selection, defined as above, could retain tendency to religious belief over atheism? We may try to find some possible candidates for appropriate for natural selection dynamics between environment and organism among such factors such as the need for social cohesion affected by human sociality and sociability, the importance of human reproduction (because religiosity and religious affiliation is correlated - however, in causally unclear and ambiguous way - with higher reproductive rate), or in looking for consolation (because psychotherapeutic support provided by religion is one of the most important functions of religious components). However, may we assume that these, definitely important factors, could lead to the evolution of religious components and could favor their development and transmission? One of main obstacles is, discussed below, the criterion of adaptation as functional design that separates function from observed results. The risk here is that someone can wrongly assign some functions to religious components when he finds correlation between religious affiliation of a given group and their better survival and/or reproduction. In ancestral environments, supernatural/religious components were expected to be too complex and too unnatural to be selectively favored for the purposes described in terms of Darwinian selection. It is the key idea of Lee Kirkpatrick's critique of adaptationist explanation of religion. He argues that religious components are too complex to fit the criteria of biological adaptation, and for this reason they 
may be easily replaced by other, non-religious traits (Kirkpatrick 2006). We may imagine that other natural and less complex phenomena are provided to achieve the above mentioned purposes. However, to avoid methodological misunderstanding it is worth indicating precisely an appropriate level of analysis. The concept of memetic adaptation states that if someone is going to measure impact of a given cultural trait on fitness, he should measure fitness of this trait, not genetic fitness of its vehicle like individual or organism (Dunbar 1998: 81). Measuring of memetic fitness shows that religious components often have a high rate of reproduction. This is a metaphorical and analogical interpretation of the Darwinian approach that is not definitely equal to a pure Darwinian account. The Darwinian explanation of culture requires looking for fitness of the vehicle of a studied cultural trait, not for fitness of that trait itself.

Cultural traits compete for human attention. Some of them are acquired and transmitted better and easier than others. They may be copied in a faithful way. Genes are transmitted from parents to offspring, while cultural traits may be transmitted not only vertically but also from all other members of community. Vertical transmission of genes guarantees its faithfulness. Transmission of ideas does not depend necessarily on their impact on fitness. That connection with fitness sometimes is necessary, in other cases is accidental. Consequently, also selectively neutral or maladaptive ideas are transmitted and spread through populations (Boyd and Silk 2015: 426). I find here the first great challenge for an opportunity of application of Darwinian account to the cultural evolution. Many cultural phenomena are not correlated with maximization of fitness, and they are transmitted and acquired independently of it. Most of them are selectively neutral. This phenomenon may be interpreted in many ways. One interpretation assumes that there is cultural equivalent of genetic noise and genetic drift that does not exclude an opportunity of adaptive nature of other cultural phenomena. Another approach assumes that selectively neutral nature of many cultural phenomena suggests that the Darwinian account is not an appropriate approach to explain cultural changes. I am familiar with this second account. Darwinian account sometimes may be successfully applied to cultural evolution but perhaps it is not the success of this method but the result of random coincidence between culture and fitness maximization.

Another problem is as follows: culture includes various phenomena, from simple clothes that protect against the cold, to the International Space Station. May we explain such different phenomena in terms of the same conceptual framework? Is the space station an extravagant byproduct of human cognitive and technological abilities, or can it be understood as something necessary for our further survival as a species (advancing space technologies, warning against threats, testing new techno- 
logies useful for the all mankind, etc.)? The problem increases when we include not only products of culture like the mentioned clothes or space station but also the ways of transmission and acquisition including language. Language is definitely necessary for human survival, reproduction, and development but it does not necessarily have to maximize fitness. This remark is reminiscent of another challenge that is another important topic in cultural and biological evolution: what phenomena may be called adaptations? Some scholars argue that the term 'adaptation' should come in degrees when it is applied to description of cultural traits. Martin Hewson points out that some cultural phenomena like cooperation or language are definitely adaptations. However, the adaptive nature of religion is still a widely discussed topic (Hewson 2013: 116). I do not discuss it here but it is worth bearing in mind that different authors in various ways define adaptation (something that must provide survival, or reproduction, or both of them). Culture, in contrast to biology, is not narrowly oriented to reproduction and even survival but includes many phenomena that are used for increasing comfort, organizing human spare time and satisfying human curiosity, just to mention a few. Obviously, we may try to explain all of them in terms of sexual selection. Like Geoffrey Miller suggests, female choice and male-male competition was important or even main force in evolution of human culture (Miller 2001). I assume that sexual selection's explanation of culture at least in some cases may not be very suitable but it is an interesting explanatory candidate to explain commonly shared traits that - at least apparently - seem to be without any survival benefits.

I treat the above mentioned cases as examples of the mismatching of the Darwinian account to the explanation of many cultural phenomena. This remark introduces the challenge of distinction on functional and symbolic design features. If religious components are functional features, they may be explained in evolutionary terms. If functional features that affect fitness change slower than symbolic traits, it may suggest that they are affected more by non-random natural selection than by random innovations. Their adaptive potential is preserved and conserved by negative purifying selection (Rogers and Ehrlich 2008). In the mentioned case of technique of boat building, the adaptive function of culture has purely biological and technological sense, and it is necessary for survival. Much more symbolical and abstract cultural features including religious ones may not play such direct biological role. It may suggest that evolution of such highly symbolic cultural traits is beyond 'interests' of natural selection. We may consider such possible explanations like mentioned sexual selection theory, or the concept of surplus brain size by-product activity, just to mention a few. This remark may work as a general rule that accepts many exemptions. One possible adaptive function of symbolic traits that may be favored by natural selection is the promoting of coordi- 
nated behaviors among mutually interested individuals because cooperation often depends on commonly shared symbols (Alvard 2003). However, as it is known, a majority of cultural traits does not work for this purpose, and the question still remains as to whether we may find for them any other adaptive functions.

George Williams (1966) argues that group fitness is the product of individual fitness of group members. The level of parents and offspring works here as a unique explanatory level. There is a distinction between the population of adapted individuals and the adapted population of individuals. Group behavior is a statistic summary of individual adaptations. The criterion of adaptation is its functional design, not its alleged results. Williams's remark provides important conclusions for the study of religion. A number of scholars are trying to explain some religious components in adaptive terms. They may fall into the trap of focusing on observed results instead of looking for possible functional design of religious features. For this reason, it is not clear what is the functional design of religious components: is their adaptive function like social cohesion or promoting reproduction, or is it internal religious worship? The following famous example provided by Williams works as a useful metaphor for all interested in applying the Darwinian approach to the study of religion. Williams noted that a group of animals huddling together in cold winter provides not only mutual heating but also channels for the spread of diseases. If every religious component is used for worship (and usually it is the case of religious components including behaviors, rituals, and beliefs), perhaps that is its unique plausible explanation. If it is true, no one should look for adaptive explanation of observed results that sometimes may be provided by religious components. For Williams, apparent group behaviors are not group functions but they work as summation of individual functions and individual behaviors. According to Williams, adaptations are designed by natural selection only for the purpose of fitness maximization of individuals that possess these adaptations. Apparent population level effects of a given adaptation are only a 'statistical by-product' (Williams 1966: 211-212, 237). Adaptationist explanation of religion fails because it explains religion in Darwinian terms as a group level adaptation. Religion works at the level of a group, while believers work at the level of an individual. The believer decides on possible usefulness of religion that may contain wide and undetermined spectrum of various kinds of applications. For this reason, there is no sense to talk about stable, general, abstract function of religion or particular religious component because the unit of religious selection is an individual believer and his personal attitude to religion. Religion is a domain of group, not individual, and there is no one person religion. However, if an individual decides how to use religious affiliation, it means that religion does not have any 
group effects that are its proper domain. This conclusion is compatible with Williams's theory of the gene and individual as the unit of selection. Furthermore, the Darwinian account of culture including religion fails in many cases because not only genes but also many environmental and behavioral factors are at work that substantially modifies individuals and groups (and, consequently, their culture) without parallel genetic modifications. Apparent correlations between genes and behavioral patterns may be the result of such factors like 'assortative mating, spatial autocorrelation, and a shared environment' as noted by Creanza et al. (2017: 7784). They argue that many models discuss the ways of transmission of cultural traits but they do not refer them to their possible genetic background and fitness (Ibid.: 7787). This remark is important for the proponents of the adaptationist explanation of religion who are looking for the impact of religious components on fitness. This point is definitely noted by Joseph Bulbulia (2008: 104) who wrote that 'though not always adaptive, religiosity evolved as a powerful fuel for biological success.' Nevertheless, some religious components seem to fit the criteria of Darwinian adaptation, if there is some correlation between the level of religiosity and reproductive rate. Religious beliefs provide obvious framework for some behavioral practices that may be interpreted as fostering life. On the other side, human species as animal species possessing sexual reproduction does not require special inputs to engage in dating, mating, and reproduction, like any other non-human animal species does. Religion and religious components cause various broad spectrum effects: from direct putative impact on survival and reproduction to definitely non-reproductive mystical and spiritual experience.

\section{CULTURAL EVOLUTION WITHOUT DARWINIAN NATURAL SELECTION}

Cultural evolution is supposed to be able to explain the processes and mechanisms of transmission of cultural traits (Brewer et al. 2017). Cultural evolution is understood here as a mechanism separated from genetic evolution because genetic evolution works slower than cultural transmission. Michael Tomasello (1999) points out that evolution of some cognitive achievements of modern humans is too rapid to fit the criteria of natural selection. Liane Gabora is one of the authors who reject the applicability of the Darwinian account to the study of culture. Her approach seems to go against dominant perspective that assumes that culture at least partially is explained in Darwinian terms, and interacts with human genome (Henrich 2015). She develops the concept of communal exchange that is an alternative to the Darwinian approach. Gabora (N.d.) argues that the Darwinian account does not explain cultural evolution because cultural traits are acquired, not inherited, and they are generated in a non-random way, by strategy and intuition. Darwinian selection ex- 
plains the transmission of inherited traits but does not explain the transmission of acquired traits and non-random variation including novelty and creativity (Gabora 2013a). Some critics point out that Gabora's approach is too broad and too radical because some cultural traits definitely may be the subjects of natural selection (Madsen and Lipo 2013: 150). Gabora adds that evolution by natural selection is a rare process in natural world. Natural selection does not work in the domain of culture in which the most important changes introduced by novelties are specially designed by humans (Gabora 2013b: 163). For Gabora, innovations are the result of non-random processes. However, many other scholars assume that innovations are the products of random processes like mutation. Gabora (Idem 2013a: 120) argues that thoughts and ideas work as genotype, while actions and artifacts work as phenotype. The selectionist account does not explain creative factors in evolution of culture; Darwinism itself explains these transmission biases. However, some critics suggest that novelty and inventions may be explained as a result of the historically long process of accumulation, blind variation, and incremental improvements (Brown and Richerson 2014: 117-118). Ross and Richerson (2014: 103) argue that there are some genetic-like processes in cultural evolution like 'random errors in teaching or acquiring items of culture (akin to mutation), statistical effects in small populations (akin to drift), and the effect of using different cultural variants on an individual's survival and reproduction (akin to natural selection).'

The Darwinian account finds and explains the similarities between humans and non-human animals in such fields like 'fight, fear, forage and fornicate,' It finds homologous mechanisms that affect such patterns but fails to explain the origin of human uniqueness as a species (Barrett, Henzi, and Lusseau 2012: 2108). Taylor Davis criticizes an idea of explaining uniquely human phenomena by biological principles that are commonly shared among various animal species. This point refers especially to religion and to human altruism that is affected by culturally inherited religious beliefs and practices (Davis 2015: 250-251). Independently on the real impact of religion on evolution of altruism, various religious texts offer examples and patterns of altruistic and self-sacrifice behaviors. This cultural coincidence is responsible for the common idea that religion and morality are linked with each other.

\section{BIOLOGICAL AND CULTURAL EVOLUTION ARE GUIDED BY} DIFFERENT RULES

One of the individual level adaptation's theory of religion, costly signaling theory assumes that strangeness and costliness of some religious components is used to develop in-group trust and cooperation (Sosis 2004: 168). This approach fails to explain origin of religion in general, and could 
be applied only to a few examples of religious practices, strongly limited to particular periods and/or regions. Many religious components are not costly. Some of them may be present, others may be absent. Anyhow, they do not have to work as honest indicator of good intentions. Religious components had and have various functions, and they definitely did not evolve only for providing exclusive in-group signs. This function of ingroup marker for a given population could be co-opted to religion and to every other unique, in-group cultural phenomenon.

In the Darwinian approach to religion, religious components are often explained as factors that were used to enhance cooperation. Of course, this function - if really supported by religious background - is successfully explained by non-Darwinian perspectives including the Durkheimian theory of religion. The human ability for large scale cooperation may be understood as the combined result of social norms and norm-psychology (Chudek and Henrich 2011: 218). Evolution of religion is a feedback with social evolution (Rappaport and Corbally 2018a, 2018b, 2018c). Religious beliefs and behaviors have affected but also were affected by social changes like division of labor, development of new modes of political organization, or development of money and writing, just to mention a few (Bellah 1964: 13065). The Darwinian approach may explain only selected cultural changes. Similarity between cultural and biological evolution is stronger in technology than art or religion. We may imagine that works of art are not correlated with increasing fitness. However, it is much more difficult to imagine that technological improvements will decrease fitness. They may do it as an unintended by-product but they are definitely invented and are used to improve our comfort, safety, health, etc. Laland (2017: 8) points out that cultural artefacts are the products of refinement and reworking, and they build cumulative culture. Cumulative culture is usually considered as a unique human feature. However, some authors treat it as a kind of social learning common at least for humans and chimpanzees (Caldwell and Millen 2008: 3530).

The difference between cultural and biological changes is seen in the way of transmission and acquisition of cultural changes. Cultural traits may be acquired and transmitted by social learning including teaching and imitation, invention, or mental simulation. Mental simulation enables anticipation of future benefits and disadvantages of implementation of a given cultural trait. It seems that there is no genetic equivalent of the function of anticipating of possible future adaptations like humans may do towards beliefs, practices, or tools. This fact shows that human culture is specially designed for a planned purpose. Biological adaptation is also specially designed but in a different way when compared to human cultural artifacts. Biological design is the result of variation that excludes and leads to extinction of the worst and the weakest forms. But variation 
itself is not designed for anything and by anyone except for genetic mutations and recombination. In the case of culture, humans may intentionally produce the best forms, and human cultural variation may include only the best, the fittest forms. Humans do not produce intentionally both weak and fit forms. Cultural evolution's computer modelling conducted by Gabora shows that invention maximizes fitness more than imitation. Culture includes phenomena that do not have any biological equivalent. Cultural evolution is the combined result of the properties of the world and of the agents (Gabora 2008). For this reason, the concept of natural selection may not be applied to the field of human culture because the causal agent of cultural evolution is conscious and intentional human agent who intentionally plans and invents the best options. We may look for other than humans, causal agents of cultural evolutionary changes and assume that human invention is always affected by environmental - natural and social as well - challenges. But, finally, human is the last agent of cultural 'natural selection' and he does not produce intentionally variation of artifacts including weak and fit forms like it is in the case of biological random genetic variation. Like Gabora points out, cultural variation is a non-random variation, in contrast to genetic random variation.

There is a strong isolation between biological lineages in contrast to cultural traits. Separated cultural lineages mix often and easily, while various biological lineages usually do not mix (Gould 1987). Stephen Gould argues that in biological evolution divergence does not lead to subsequent joining of divergent lineages. Biological lineage, once diverged, does not combine again. Divergence and branching is a basic biological process that excludes again connection of various separated genetic lineages. In cultural evolution, divergent lineages often combine and join, and it is one of the basic phenomena in cultural evolution (Idem 1991). We may talk about transmission and joining between various cultures but we can almost never find it between species. Biological evolution is a branching tree-like process. Cultural evolution works as blending process and is based on reticulation and hybridization like, for instance, the mixing of various languages or religious syncretism. However, as Gray, Greenhill, and Ross (2007: 365-366) suggest, hybridization occurs also in biology among plant and animal species. Independently on possible cases of hybridization in biology, cultural phylogeny is rather a blending process in which various cultural lineages merge into one, rather than the branching process in which one lineage branches into several new lineages (tree-like concept of phylogeny) (Reisman 2013: 434).

Evolution of cultural traits is strongly context and subject dependent. Not all cultural factors evolve in the same way. Language is an exceptional cultural phenomenon in the sense of its evolutionary stability. Language is inherited in early childhood from parents to their offspring with- 
out modifications. This vertical transmission is very precise and is supported by strategic usefulness of language for communication. Evolution of language is a very slow process in contrast to the rapid evolution of many other cultural traits. The speed and easiness of modification of a given cultural trait depends on its strategic usefulness and social importance. Language is much more important for survival and reproduction than other traits. Its possible modifications at least partially should fit the criteria of biological adaptation. It means that evolution of language is regulated by its impact on survival and reproduction more than other cultural traits that do not have to be connected with fitness maximization. Not all cultural traits including language may be modified quickly and in a revolutionary way.

Religion is also modification-resistant but sharing common religious beliefs and rituals does not provide the same adaptive value for individuals in the same way that sharing the same language and cognitive ability helps to develop early language skills. There are at work various causal agents of evolutionary change. In the case of religion, modifications often have been caused by official authorities. However, evolutionary change sometimes has been affected by believers. This latter kind of modifications could be compatible with the concept of theological (in)correctness developed by CSR. Evolution of religion is slower than other cultural traits like habits, ethical norms or legal rules. Religious ethical systems do not accept or accept late changes that are introduced by secular systems.

The Darwinian account is too narrow to explain complexity and capacity of human mind. If natural selection is a non-random process of production of the best adaptations in the current environment, it is not clear why it generates such highly advanced mind that possesses creating culture abilities. Humans need much simpler mind to survive. Evolution of human mind went beyond the requirements of the ancestral environment. Many cultural and social traits that were affected by this highly advanced mind, were and are disadvantageous. Many cultural traits are maladaptive. According to Tim Ingold (2004: 211-212, 217), reduction of biology to genetics is responsible for possible explanatory difficulties in the explanation of cultural evolution by biological evolution. The Darwinian account does not explain the acquired and culturally transmitted traits that make humans special. It is assumed that acquired traits have replaced instinct-like innate traits (Wunn, Urban, and Klein 2012).

Cultural traits are often transformed and modified during transmission, and they do not replicate like genes. Consequently, cultural traits are the subject of frequent mutations. In biological evolution, natural selection works when the rate of mutation is very low (Sperber 1996). Low level of mutations that is required by natural selection is impossible to achieve in cultural transmission in which ideas are constructed and 
reconstructed (Acerbi and Mesoudi 2015: 486). Reconstruction of ideas, beliefs or behaviors is a cultural equivalent of genetic mutation. Cultural traits are often reconstructed and dynamically shaped by learners. They are not faithfully transmitted despite the fact that the mechanisms of transmission in cultural evolution are based on observation. For this reason, cultural evolution is preservative and reconstructive as well (Claidière, Scott-Phillips, and Sperber 2014: 3). If we take that specificity of cultural evolution to the field of religion, we find that believers modify personally their beliefs, and they treat very selectively religious components. For this reason, it is hard to say about faithful transmission and unity of individual perception of religious components and, in consequence, their unique, commonly shared adaptive function.

\section{RELIGION STILL REMAINS UNEXPLAINED FROM A DARWINIAN POINT OF VIEW}

Humans have an ability to have fast adaptations because environment in Pleistocene was very flexible. This environment could reduce the number and impact of fixed behavioral patterns and could increase an ability to adopt new patterns in new and current cultural contexts. In this model, instincts should be ready to be replaced by new patterns that were and are acquired in the current context (Wunn and Grojnowski 2016: 64). As it is assumed in both evolutionary and functional approach to religion, one of the mechanisms of control of social life is formed by religious components. Benefits for the entire group require mutual cooperation that is difficult to evolve and to maintain. For this reason, some cultural tools including religions are considered as necessary (Wilson 2002). However, some scholars like Peter J. Richerson and Morten H. Christiansen argue that various cultural fields affect survival and reproduction in different ways. Variation in science and technology cause more important consequences for survival and reproduction than variation in language or religion (Richerson and Christiansen 2013: 12). As I pointed earlier, we could consider language as more important for fitness than religion but both of them are considered as less important than science and technology. Some cultural traits could be analyzed in Darwinian terms but others including religious components seem to be too weak and not too significant for explanation in terms of natural selection. The term 'adaptation' comes in degrees in cultural evolution, and we should not overestimate the adaptive role of cultural traits.

Evolutionary explanation of religion seems to be a great explanatory puzzle for the following reason. If natural selection eliminates traits that are costly and that do not maximize fitness, it is puzzling why natural selection did not stop development of religious components that are costly and counterintuitive (Slingerland, Henrich, and Norenzayan 2013: 336). 
Religious components seem at least superficially to be counter-adaptive or even maladaptive. They are costly in terms of cognition, time, energy, or emotions (Murray and Goldberg 2009: 181). They could become useful and adaptive later but at the beginning they were too costly in comparison with other possible cultural tools. Religion may be explained in terms of functionality and rationality that is affected by particular conditions of a given ecological niche (Reynolds and Tanner 1985). Evolutionary cultural account treats humans like functional units that use cultural evolution to adapt to the environment. Wilson et al. use the concept of group-level functional organization. They find some adaptive reasons that make religious groups more advantageous at the level of inter-group competition like high rate of genetic relatedness, social ties between unrelated peers, or strong impact of ethical system. 'Loose' culture may promote invention of novelty because individuals may freely look for new solutions of given problems and the entire group may adapt to new environmental conditions (Wilson et al. 2017: 136, 139, 143). However, Wilson's concept of grouplevel functional organization is criticized. Some critics show discrepancies between this model and real human behaviors. Human groups do not work as functional units and they are not species-like entities because humans may belong to various cultural communities (Palmer 2017: 159$160)$. Despite these critical remarks, the capacity to acquire religious beliefs could be considered as genetically coded if the possessing of religious beliefs made believers more fit in terms of natural selection.

The Darwinian approach to religion could work if we accept the concept of cultural group as adaptive unit. We should be especially careful when we talk about group adaptations and group functions. Instead we should consider such terms like the sum of individual adaptations and individual functions. However, Wilson talks about biological transitions from 'groups of organisms to groups as organisms.' He assumes that many traits evolved because they were beneficial for group and they provided fitness for group, not for individuals. All functional traits may be products of blind variation and selective retention (Wilson 2009: 323-324, 332). We could accept the Darwinian account to religion, if we prove that group selection works - because religion is a domain of a group, not individual - and then that religious components could be the subject of blind variation and natural selection. However, it is difficult because cultural evolution including religion works differently from the biological one.

Sociobiological approach (Wilson, Trivers, and Dawkins) treats culture as every other non-genetic evolutionary process. It is assumed here that the proximate function of culture is to contribute to reproduction, and the ultimate function is to contribute to genetic descent. Culture works in evolutionary terms if it affects genetic descent. Religion may work as both adaptive and maladaptive niche construction. Conservative religion is adaptive 
if it stops development and implementation of new values and behaviors. The conservative account introduces a cautious approach to new technologies and habits. Conservative religious beliefs are maladaptive when they inhibit adaptive reactions towards changes. Genetic evolution is a very slow process. For this reason, it does not protect human populations against their wrong attitudes towards apparently beneficial cultural changes. Religion may be a deleterious niche construction that inhibits development of another niche construction like science and technology (Odling-Smee 1995: 5-6, 35-36).

Religion may be understood as the product of human inventiveness like many other cultural phenomena. Pro-natalist religious approach may be explained in Darwinian terms because religious beliefs and patterns regulate conditions for conception and birth, adolescent sexuality, or marriage and divorce. These regularities fluctuate dynamically between optimization and maximization of fitness and reproduction. In various environments, cultural traits including religious ones may favor optimization or maximization of reproductive strategies. Religiously regulated reproductive rate is highly context dependent and affected by such factors like the rate of mortality and existential security. The less available energy resources and smaller incomes per capita, the more restrictive are religious pro-natalist rules that forbid contraception, abortion, and favor faster life strategies. In better economic conditions, religions encourage a slower rate of reproduction. Reynolds and Tanner (1985: 131, 134-136, 142,149 , and 151) point out that 'religions everywhere take a very close interest in human biology.' These kinds of religious components may regulate survival and reproduction but it is not clear if we should explain them in Darwinian terms. It is worth adding that in some Christian denominations, contraception is now allowed as well as homosexuality. But some others still do not allow it. This case makes mentioned religious impact more flexible than adaptationist account assumes in general.

Religion seems to be a special case in cultural and biological evolution. Many scholars claim that religion is not an adaptation even if many other cultural traits may be explained in Darwinian terms. Some of them do it because they treat religion as something more than a tool that was specially designed for fitness maximization. Others including Todd Tremlin note that religion does not fit the definitional criteria of adaptation. He found, among others, that alleged adaptive context of religion does not explain ultimately the origin of religious thinking. It may suggest that religion may be something more than a tool designed for enhancing survival and reproduction. Other remarks suggest that religion has not been specially designed for providing adaptive functions like social cohesion but religious components could instead be used as secondary cultural support for socially beneficial behaviors when they have been invented 
(Tremlin 2013: 39-40). Gene-culture coevolution explains religious beliefs as cognitive by-products or by-products of other adaptations that are originally useless. However, religious beliefs may be coopted to other adaptive functions and then they may be favored by cultural evolution (Bulbulia et al. 2013: 393). The critics of Darwinian approach to religion argue that human behaviors and culture are affected by particular social context. Society is a primary force that affects behaviors. However, humans shape society at least partially according to their biological benefits. Robin I. M. Dunbar argues that cultural transmission enables fast adapting to new environmental conditions that cannot be provided by genetic response. For this reason, long-lived human species could avoid extinction. Imitation and social learning in cultural transmission enable avoiding long and unpredictable trial-and-error method (Dunbar 1998: 73, 80).

A population that consists of well-adapted individuals may be not as well-adapted as another population because it may exploit resources too fast without a long-term perspective. A Darwinian approach to culture including religion would work if adaptation is the main power that affects function and development of culture. However, adaptation is one of many possible factors. Reproduction and transmission of cultural trait is affected by its survival and cultural value. Cultural evolution is driven also by choice and consciousness. Individuals may intentionally prefer a given trait for the reason of expected benefits (Morphy 1998: 100-101, 103104, 111). Joseph Fracchia and Richard C. Lewontin (1999: 73) point out that cultural evolution is a domain of acquisition rather than transmission because the individual is placed in a set of many cultural traits that he acquired in his lifetime.

\section{CONCLUSION}

Evolutionary terms are commonly applied to the study of culture including religion. When we apply Darwinian approach to religion, we have to look for adaptations and for possible connections between religious beliefs and fitness maximization. We may find some cultural traits that maximize fitness. They may be a subject of selective pressure for a given design that is preserved in population because it provides better reproduction than other traits.

When we talk about Darwinian approach to religion, we should have in mind two levels of fitness maximization: fitness of cultural units, and fitness of their vehicles. In the first case, some cultural traits have better fitness than others. In the latter case, we may find only accidental and apparent correlation between fitness of cultural units and their vehicles. For this reason, we may apply Darwinian terms more to describe processes of cultural transmission of religious components than to the rate of survival 
and reproduction of people who possess these traits. But it is not Darwinian in a strict sense.

My idea is that other evolutionary theories explain better - if not better generally, definitely better at least in some contexts and in regard to particular traits - evolution and dissemination of religious components. Among such theories are Lamarckism that explains transmission of acquired traits, and sexual selection theory of religion. The latter seems a very promising candidate that - in my opinion - may explain much more religious components and contexts of their application than Darwinian selection can. It is much easier to accept the idea that a given religious component, at least apparently useless, evolved as the product of male-male competition and female choice (much less, if any, female-female competition and male choice) than looking for any adaptive justification of that trait. Obviously, a follower of Darwinian account may always say that a given religious trait is a by-product of another one. However, the same trait that is nonadaptive in Darwinian terms of survival may be adaptive in terms of sexual attraction for possible mates, as fitness indicator or Zahavi's handicap principle, just to name a few possibilities.

\section{NOTE}

${ }^{1}$ Although the idea of cultural evolution has been discussed for several decades starting, among others, in Cavalli-Sforza and Feldman (1981) and Boyd and Richerson (1985), this field is still in statu nascendi. Many recently published papers still discuss the basic, definitional topics and concepts, including PNAS special issue 'Sackler Colloquium on Extension of Biology through Culture', 2017, 114 (30); published ahead of print July 25, 2017.

\section{REFERENCES}

Acerbi, A., and Mesoudi, A. 2015. If We are All Cultural Darwinians What's the Fuss about? Clarifying Recent Disagreements in the Field of Cultural Evolution. Biol Philos 30 (4): 481-503.

Alvard, M. S. 2003. The Adaptive Nature of Culture. Evolutionary Anthropology 12: $136-149$.

Barrett, L., Henzi, S. P., and Lusseau, D. 2012. Taking Sociality Seriously: The Structure of Multi-Dimensional Social Networks as a Source of Information for Individuals. Phil. Trans. R. Soc. B 367 (1599): 2108-2118.

Bellah, R. N. 1964. Religious Evolution. American Sociological Review 29 (3): 358-374.

Boyd, R., and Silk, J. B. 2015. How Humans Evolved. New York - London: W. W. Norton \& Company.

Brewer, J. M., Gelfand, J. C., Jackson, I. F., MacDonald, P. N., Peregrine, P. J., Richerson, P., Turchin, P., Whitehouse, H., and Wilson, D. S. 2017. Grand Challenges for the Study of Cultural Evolution. Nature Ecology \& Evolution 1, 0070. DOI: $10.1038 / \mathrm{s} 41559-017-0070$. 
Brown, G. R., and Richerson, P. J. 2014. Applying Evolutionary Theory to Human Behaviour: Past Differences and Current Debates. Journal of Bioeconomics 16: $105-128$.

Bulbulia, J. 2008. Meme Infection or Religious Niche Construction? An Adaptationist Alternative to the Cultural Maladaptationist Hypothesis. Method \& Theory in the Study of Religion 20 (1): 67-107.

Bulbulia, J. et al. 2013. The Cultural Evolution of Religion. In Richerson, P. J., and Christiansen, M. H. (eds.), Cultural Evolution (pp. 381-404). Cambridge, MA: MIT Press.

Caldwell, Ch. A., and Millen, A. E. 2008. Studying Cumulative Cultural Evolution in the Laboratory. Phil. Trans. R. Soc. B 363: 3515-3528.

Chudek, M., and Henrich, J. 2011. Culture-Gene Coevolution, Norm-Psychology and the Emergence of Human Prosociality. Trends in Cognitive Sciences 15 (5): 218-226.

Claidière, N., Scott-Phillips, T. C., and Sperber, D. 2014. How Darwinian is Cultural Evolution? Phil. Trans. R. Soc. B 369 (1642): 20130368. http://dx.doi. org/10.1098/rstb.2013.0368.

Creanza, N., Kolodny, O., and Feldman, M. W. 2017. Cultural Evolutionary Theory: How Culture Evolves and Why it Matters. PNAS 114 (30): 7782-7789.

Davis, T. 2015. Group Selection in the Evolution of Religion: Genetic Evolution or Cultural Evolution? Journal of Cognition and Culture 15: 235-253.

Dunbar, R. I. M. 1998. Behavioural Adaptation. In Harrison, G. A., and Morphy, H. (eds.), Human Adaptation. Oxford - New York: Berg.

Fracchia, J., and Lewontin, R. 1999. Does Culture Evolve? History and Theory 38 (4): $52-78$.

Gabora, L. N.d.. The Creative Process of Cultural Evolution. In Leung, A., Kwan, L., and Liou, S. (eds.), Handbook of Culture and Creativity: Basic Processes and Applied Innovations. Oxford: Oxford University Press. In Press.

Gabora, L. 2008. Modeling Cultural Dynamics. Proceedings of the Association for the Advancement of Artificial Intelligence (AAAI) Fall Symposium. November 7-9, Arlington VA (pp. 18-25). Menlo Park, CA: AAAI Press.

Gabora, L. 2013a. An Evolutionary Framework for Cultural Change: Selectionism Versus Communal Exchange. Physics of Life Reviews 10: 117-145.

Gabora, L. 2013b. Reply to the Commentaries on An Evolutionary Framework for Cultural Change: Selectionism Versus Communal Exchange: Physics of Life Reviews 10: 162-167.

Gould, S. J. 1987. An Urchin in the Storm. New York: W. W. Norton.

Gould, S. J. 1991. Bully for Brontosaurus. New York: Norton.

Gray, R. D., Greenhill, S. J., and Ross, R. M. 2007. The Pleasures and Perils of Darwinizing Culture (with Phylogenies). Biological Theory 2 (4): 360-375.

Henrich, J. 2015. The Secret of Our Success. How Culture is Driving Human Evolution, Domesticating our Species, and Making us Smarter. Princeton, NJ: Princeton University Press. 
Hewson, M. 2013. Consensus and Dissensus on Cultural Evolution: A Commentary on David Sloan Wilson. Social Evolution Forum, D. S. Wilson, Human Cultures are Primarily Adaptive at the Group Level, Cliodynamics: The Journal of Theoretical and Mathematical History 4: 102-138.

Ingold, T. 2004. Beyond Biology and Culture. The Meaning of Evolution in a Relational World. Social Anthropology 12 (2): 209-221.

Kirkpatrick, L. A. 2006. Religion is Not an Adaptation. In McNamara, P. (ed.), Psychology, Religion, and Spirituality. Where God and Science Meet. How Brain and Evolutionary Studies Alter our Understanding of Religion. Vol. 1. London: Praeger.

Laland, K. 2017. Darwin's Unfinished Symphony. How Culture Made the Human Mind. Princeton, NJ: Princeton University Press.

Madsen, M. M., and Lipo, C. P. 2013. Saving Culture from Selection. Comment on 'An Evolutionary Framework for Cultural Change: Selectionism Versus Communal Exchange' by L. Gabora. Physics of Life Reviews 10: 149-150.

Miller, G. 2001. The Mating Mind. How Sexual Choice Shaped the Evolution of Human Nature. New York: Anchor Books.

Morphy, H. 1998. Cultural Adaptation. In Harrison, G. A., and Morphy, H. (eds.), Human Adaptation (pp. 99-150). Oxford - New York: Berg.

Murray, M. J., and Goldberg, A. 2009. Evolutionary Accounts of Religion: Explaining and Explaining Away. In Schloss, J., and Murray, M. J. (eds.), The Believing Primate. Oxford: Oxford University Press.

Odling-Smee, J. 1995. Biological Evolution and Cultural Change. In Jones, E., and Reynolds, V. (eds.), Survival and Religion. Biological Evolution and Cultural Change. New York: John Wiley and Sons.

Palmer, C. T. 2017. Don't Worry, Be Funded! Religion, Brain \& Behavior 7 (2): $159-160$.

Rappaport, M. B., and Corbally, C. 2018a. Evolution of Religious Capacity in the Genus Homo: Origins and Building Blocks. Zygon 53: 123-158.

Rappaport, M. B., and Corbally, C. 2018b. Evolution of Religious Capacity in the Genus Homo: Cognitive Time Sequence. Zygon 53: 159-197.

Rappaport, M. B., and Corbally, C. 2018c. Evolution of Religious Capacity in the Genus Homo: Trait Complexity in Action Through Compassion. Zygon 53: 198-239.

Reisman, K. 2013. Cultural Evolution. In Ruse, M. (ed.), The Cambridge Encyclopedia of Darwin and Evolutionary Thought. Cambridge: Cambridge University Press.

Reynolds, V., and Tanner, R. 1985. The Effects of Religion on Human Biology. In Durant, J. (ed.), Darwinism and Divinity. Essays on Evolution and Religious Belief. Oxford: Basil Blackwell.

Richerson P. J., and Boyd, R. 2005. Not by Genes Alone: How Culture Transformed Human Evolution. Chicago, IL: University of Chicago Press.

Richerson, P. J., and Christiansen, M. H. 2013. Introduction. In Richerson, P. J., and Christiansen, M. H. (eds.), Cultural Evolution. Cambridge, MA: MIT Press. 
Rogers, D. S., and Ehrlich, P. R. 2008. Natural Selection and Cultural Rates of Change. PNAS 105 (9): 3417-3419.

Ross, C. T., and Richerson, P. J. 2014. New Frontiers in the Study of Human Cultural and Genetic Evolution. Current Opinion in Genetics \& Development 29: 103-109.

Rothman, S. 2015. The Paradox of Evolution. The Strange Relationship between Natural Selection and Reproduction. Amherst, New York: Prometheus Books.

Slingerland, E., Henrich, J. and Norenzayan, A. 2013. The Evolution of Prosocial Religions. In Richerson, P. J., and Christiansen, M. H. (eds.), Cultural Evolution. Cambridge, MA: MIT Press.

Sosis, R. 2004. The Adaptive Value of Religious Ritual. American Scientist 92 (2): $166-172$.

Sperber, D. 1996. Explaining Culture: A Naturalistic Approach. Oxford: Blackwell.

Tomasello, M. 1999. The Cultural Origins of Human Cognition. Cambridge, MA: Harvard University Press.

Tremlin, T. 2013. Evolutionary Religious Studies. Notes on a Unified Science of Religion. In Dawes, G. W., and MacLaurin, J. (eds.), A New Science of Religion. New York: Routledge.

Whiten, A., Ayala, F. J., Feldman, M. W., and Laland, K. N. 2017. The Extension of Biology Through Culture. PNAS 114 (30): 7775-7781.

Williams, G. 1966. Adaptation and Natural Selection: A Critique of Some Current Evolutionary Thought. Princeton, New Jersey: Princeton University Press.

Wilson, D. S. 2002. Darwin's Cathedral: Evolution, Religion, and the Nature of Society. Chicago: University of Chicago Press.

Wilson, D. S. 2009. Evolutionary Social Constructivism: Narrowing (but not yet Bridging) the Gap. In Schloss, J., and Murray, M. J. (eds.), The Believing Primate (pp. 318-338). Oxford University Press.

Wilson, D. S., Hartberg, Y., MacDonald, I., Lanman J. A., and Whitehouse, H. 2017. The Nature of Religious Diversity: A Cultural Ecosystem Approach. Religion, Brain \& Behavior 7 (2): 134-153.

Wunn, I., and Grojnowski, D. 2016. Ancestors, Territoriality, and Gods. Springer.

Wunn, I., Urban, P., and Klein, C. 2012. The Ethology of Religion: The Biological Roots of Religious Behavior. Conference: EASR Annual Conference, IAHR Special Conference, Södertörn University, Stockholm 11. 